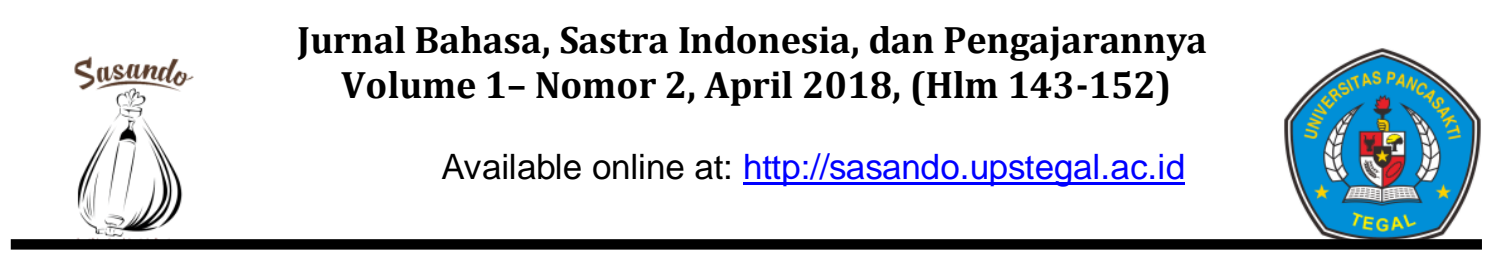

UPAYA MENINGKATKAN HASIL BELAJAR SISWA DALAM PENGGUNAAN METODE

MIND MAP PADA PEMBELAJARAN BAHASA INDONESIA TENTANG TEKNOLOGI

(Kelas IV SD Negeri Kemantran o1)

\title{
Lyswidia Andriarsih
}

Dosen di Sekolah Tinggi Agama Islam Bakti Negara (STAIBN)

Jalan Jeruk No. 9 procot slawi kabupaten Tegal 52412 Telp. (o283) 491277

\begin{abstract}
Abstrak
Pelaksanaan upaya meningkatkan hasil belajar siswa dalam penggunaan metode mind map pada pembelajaran Bahasa Indonesia materi perkembangan teknologi di kelas IV SD Negeri Kemantran 01 Kec. Kramat Kab. Tegal menggunakan jenis penelitian ini yang merupakan penelitian tindakan (action research), karena penelitian dilakukan untuk memecahkan masalah pembelajaran di kelas. Berdasarkan data yang ketuntasan hasil belajar siswa kelas IV pembelajaran perkembangan teknologi yang memenuhi KKM hanya 4 siswa, sedangkan siswa yang belum memenuhi KKM sebanyak 19 siswa. Pada siklus I siswa yang memenuhi KKM sebanyak 16 siswa dan yang memenuhi KKM sebanyak 7 siswa. Sedangkan pada siklus II siswa yang memenuhi KKM 20 siswa dan yang belum memenuhi KKM sebanyak 3 siswa.
\end{abstract}

Kata kunci: mindmap, hasil belajar

Abstract

Using this type of research is an action research (action research), because the research carried out to solve the problem of learning in the classroom. The study also included a descriptive study, because mengmultimediakan how an applied learning and what is desired can be achieved. Based on data mastery learning outcomes of fourth grade students learning technology development that meets the KKM only four students , whilestudents who do not meet the KKM many as 19 students. In the first cycle of students who meet the KKM as many as 16 students who meet KKM 7 students. While on the second cycle students yng meet KKM 20 students and who have not met the KKM as many as three student.

keywords: mindmap, subject learning 


\section{PENDAHULUAN}

Pendidikan merupakan salah satu modal pembangunan karena sasarannya adalah untuk menciptakan Sumber Daya Manusia yang berkualitas. Melalui pendidikan, suatu negara dapat mencapai tujuan-tujuannya baik untuk mengembangkan kepribadian bangsa maupun memajukan kehidupan dan kesejahteraaan bangsa. Menurut Tilar (dalam Mikarsa, 1999:28) hakikat pendidikan sebagai suatu proses menumbuhkembangkan eksistensi

peserta didik yang membudaya dalam tata kehidupan yang berdimensi lokal, nasional, dan global.

Dalam penelitian ini mengungkapkan tentang permasalahan yang terjadi di kelas IV SD tentang pembelajaran bahasa Indonesia dengan materi perkembangan teknologi. Menurut Rasmini dalam Nurjanah, (2014:14) pentingnya sebuah pembelajaran bahasa Indonesia yang memiliki peran dan fungsi sebagai sarana utama untuk berbahasa. Tujuan pengajaran Bahasa Indonesia di SD secara umum mengacu pada kemampuan, memahami bahasa Indonesia dari segi bentuk, makna, dan fungsi serta menggunakannya secara tepat dan kreatif untuk bermacammacam tujuan, dan keadaan secara lisan ataupun tertulis.

Salah satu alternatif yang dapat disajikan guru agar pembelajaran bahasa Indonesia tidak membosankan, dan mampu untuk meningkatkan partisipasi aktif siswa dalam kelangsungan proses pembelajaran adalah dengan mendesain penyajian pembelajaran bahasa Indonesia dengan menerapkan metode yang menarik dan kreatif. Penggunaan metode mengajar yang tepat oleh seorang guru dalam proses belajar mengajar sangat berpengaruh terhadap keberhasilan mengajar.

Atas dasar pemikiran tersebut maka penulis melakukan Penelitian Tindakan Kelas (PTK) dengan judul "Usaha Meningkatkan Hasil Belajar Siswa dengan Menggunakan Metode Mind Map pada Pembelajaran Bahasa Indonesia tentang Perkembangan Teknologi (Penelitian Tindakan Kelas pada Pembelajaran bahasa Indonesia di Kelas IV SD Negeri Kemantran o1 kecamatan Kramat kabupaten Tegal.

Referensi pustaka atau sumber yang relevan sesuai dengan penelitian

adalah penelitian milik Hanifah, (2009)

$$
\text { persamaannya }
$$
penelitian ini menggunakan model yang sama hanya berbeda mata pelajarannya.

\section{METODE}

Jenis penelitian

Dengan menggunakan jenis penelitian ini merupakan penelitian tindakan (action research) karena penelitian dilakukan untuk memecahkan masalah pembelajaran di kelas. Penelitian ini juga termasuk penelitian deskriptif, sebab

mengmultimediakan bagaimana suatu pembelajaran diterapkan dan apayang diinginkan dapat dicapai.

\section{Waktu dan Tempat Penelitian}

Waktu yang diperlukan peneliti untuk melakukan penelitian tindakan kelas di SD Negeri 
Kemantran 01 adalah 2 minggu dengan 2x pertemuan, senin minggu ke tiga dan rabu minggu ke empat bulan Oktober 2017. Tempat penelitian di SD Negeri Kemantran 01 kecamatan Kramat

Siklus PTK yang dikembangkan Kemmis dan Mc Tagart (Arikunto, 2010)

\section{Perencanaan (Planning)}

Tahap ini merupakan tahap dimana peneliti mempersiapkan segala keperluan penelitian sebelum melakukan action/ tindakan di lapangan.

\section{Pelaksanaan atau tindakan (Acting) \\ Menurut Arikunto (2010) menyatakan bahwa "Tahap pelaksanaan merupakan implementasi atau penerapan isi rancangan yaitu menggunakan tindakan kelas".}

\section{Pengamatan (Observing)}

Tahap ini merupakan tahap pengumpulan berbagai data yang diamati dari fenomena yang terjadi pada saat perlakuan atau pemberian tindakan itu berlangsung.

\section{Refleksi (Reflecting)}

Pada langkah ini peneliti mengkaji, melihat, dan mempertimbangkan atas hasil atau dampak dari tindakan dari berbagai kriteria.

\section{Data, Instrumen, dan Teknik Pengumpulan Data}

Sumber data dalam penelitian ini adalah siswa kelas IV SD Negeri Kemantran o1 dan guru kelas IV. Data yang diperoleh dari berbagai instrumen pada tahap ini yang meliputi observasi dan tes hasil belajar yang dikumpulkan. Data-data tersebut kemudian dikelompokkan ke dalam data kualitatif dan data kuantitatif

1. Data Kualitatif

Data kualitatif diperoleh dari instrumen pengumpul data yaitu observasi.

2. Data Kuantitatif

Data kuantitatif diperoleh dari tes hasil belajar.

Teknik pengumpulan data dalam penelitian ini terdiri dari:
a. Wawancara
b. Tes
c. Refleksi (Reflecting)
d. Dokumentasi
e. Observasi

\section{Teknik Analisis Data}

Analisis data dilakukan selama penelitian dari awal sampai akhir.. Berdasarkan analisis data yang akan dilakukan peneliti, rincian analisis data yaitu sebagai berikut:

Analisis Hasil Observasi

Data observasi menggunakan skala penilaian dengan rentang nilai dalam bentuk angka $(4,3,2,1)$ untuk penilaian proses pembelajaran yang dilakukan oleh guru dan siswa dalam pembelajaran yang berarti angka $4=$ sangat baik, 3 = baik, $2=$ cukup, dan $1=$ kurang.

Tabel $3 \cdot 9$

Kriteria Interpretasi Hasil Observasi Untuk Guru dan Siswa 


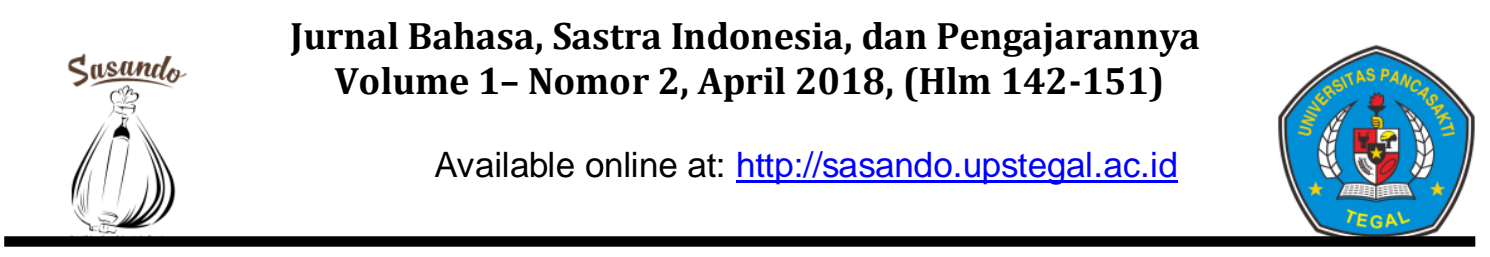

\begin{tabular}{|l|l|}
\hline Besar persentase \% & Interpretasi \\
\hline $81-100 \%$ & Sangat Baik \\
\hline $61-80 \%$ & Baik \\
\hline $41-60 \%$ & Cukup \\
\hline $21-40 \%$ & Kurang \\
\hline $0-20 \%$ & $\begin{array}{l}\text { Sangat } \\
\text { Kurang }\end{array}$ \\
\hline
\end{tabular}

Sumber: (Riduwan, 2012)

Adapun kriteria keberhasilan yang harus dicapai pada observasi guru dan siswa yaitu mencapai kriteria baik atau sangat baik indikator muncul (61\%

- 100\%).

Analisis Hasil Belajar Siswa

Penilaian dapat dilihat pada tabel berikut:

Tabel 3.2 Pedoman penilaian

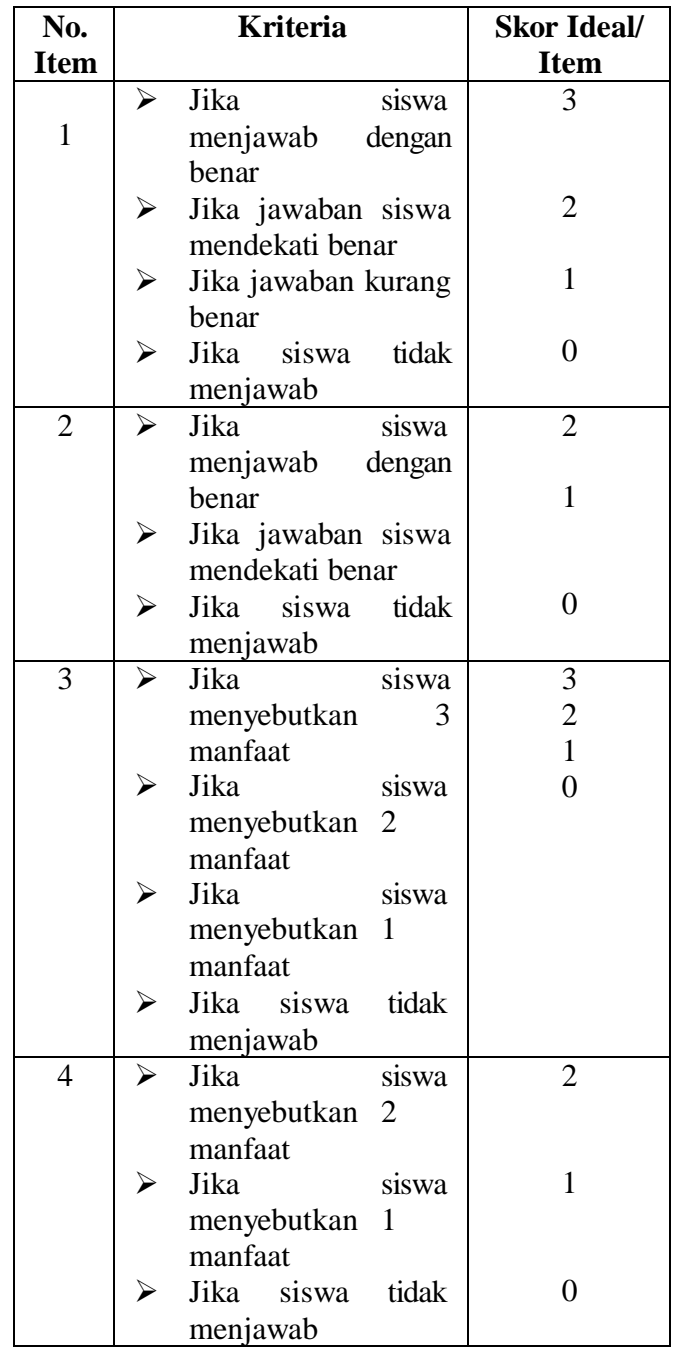

\begin{tabular}{|c|c|c|}
\hline 5 & $\begin{aligned} &> \text { Jika siswa } \\
& \text { menjawab dengan } \\
& \text { benar }\end{aligned}$ & 0 \\
\hline 6 & $\begin{aligned} &> \text { Jika siswa } \\
& \text { menyebutkan } 3 \text { alat } \\
&> \text { Jika siswa } \\
& \text { menyebutkan 2 alat } \\
&> \text { Jika siswa } \\
& \text { menyebutkan 1 alat } \\
&> \text { Jika siswa tidak } \\
& \text { menjawab } \\
&\end{aligned}$ & 3 \\
\hline 7 & $\begin{array}{ll}> & \text { Jika siswa } \\
& \text { menyebutkan } 3 \text { alat } \\
> & \text { Jika siswa } \\
& \text { menyebutkan 2 alat } \\
> & \text { Jika siswa } \\
& \text { menyebutkan 1 alat } \\
> & \text { Jika siswa tidak } \\
\text { menjawab }\end{array}$ & 1 \\
\hline 8 & $\begin{aligned} &> \text { Jika siswa } \\
& \text { menjawab dengan } \\
& \text { benar } \\
&> \text { Jika jawaban siswa } \\
& \text { mendekati benar } \\
&> \text { Jika siswa tidak } \\
& \text { menjawab } \\
&\end{aligned}$ & 2 \\
\hline 9 & $\begin{aligned}> & \text { Jika siswa } \\
& \text { menyebutkan 2 alat } \\
> & \text { Jika siswa } \\
& \text { menyebutkan 1 alat } \\
> & \text { Jika siswa tidak } \\
& \text { menjawab }\end{aligned}$ & 2 \\
\hline 10 & $\begin{array}{ll} & \text { Jika siswa } \\
& \text { menyebutkan 2 alat } \\
> & \text { Jika siswa } \\
& \text { menyebutkan 1 alat } \\
> & \text { Jika siswa tidak } \\
& \text { menjawab }\end{array}$ & 2 \\
\hline
\end{tabular}

Dikatakan penelitian ini berhasil atau tuntas jika $75 \%$ memenuhi KKM. Artinya minimal 26 orang siswa telah mencapai nilai KKM dengan ketentuan pada KKM yang sudah ditetapkan terhadap mata pelajaran Bahasa Indonesiadi kelas IV SD Negeri Kemantran o1 sebagai berikut: 


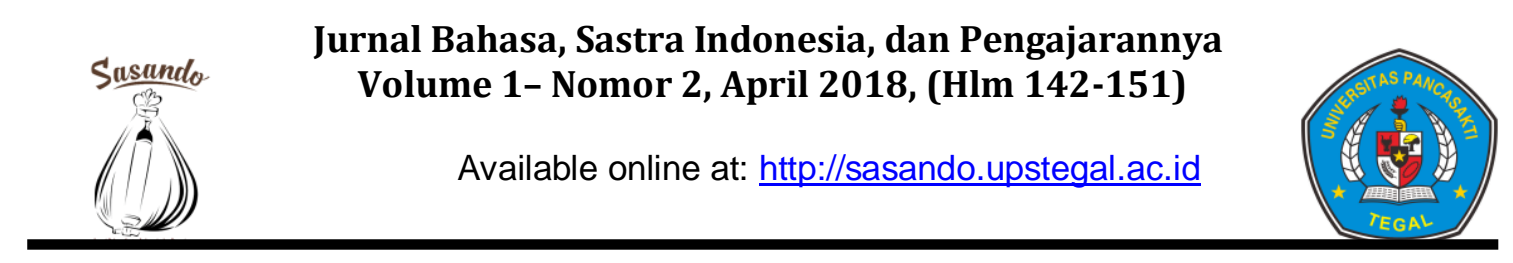

\begin{tabular}{|l|l|}
\hline 60 & Tuntas \\
\hline$<60$ & Tidak Tuntas \\
\hline
\end{tabular}

\section{HASIL DAN PEMBAHASAN}

Ada tiga pertanyaan pada penelitian ini.

1. Bagaimana perencanaan upaya meningkatkan hasil belajar siswa dalam penggunaan metode mind map pada pembelajaran bahasa Indonesia materi perkembangan teknologi di kelas IV SD Negeri Kemantran 01 kecamatan Kramat kabupaten Tegal?

2. Bagaimana pelaksanaan upaya meningkatkan hasil belajar siswa dalam penggunaan metode mind map pada pembelajaran bahasa Indonesia materi perkembangan teknologi di kelas V SD Negeri Kemantran 01 kecamatan Kramat kabupaten Tegal?

3. Bagaimana hasil belajar dalam penggunaan metode mind map pada pembelajaran bahasa Indonesia materi perkembangan teknologi di kelas IV SD Negeri Kemantran 01 kecamatan Kramat kabupaten Tegal?

Peneliti mencoba menggunakan metode Mind Map pada pembelajaran Bahasa Indonesia. Penelitian ini diharapkan dapat memberikan cara baru dalam penyampaian pembelajaran khususnya materi bahasa Indonesia. Ada dua siklus dalam penelitian ini, siklus 1 dan 2.

Perencanaan upaya meningkatkan hasil belajar siswa dalam penggunaan metode mind map.

Siklus I

Usaha meningkatkan kualitas pembelajaran bahasa Indonesia, materiperkembangan teknologi kelas IV SD Negeri Kemantran 01, menggunakan metode pembelajaran Mind Map hasilnya sebagai berikut.

\section{Perencanaan}

Pada

perencanaan

tindakan pembelajaran

siklus 1 , terdiri dari satu pertemuan. Pembelajan mengacu pada standar kompetensinya yaitu bentuk teknologi, namanya, kemajuan teknologi di lingkungan kabupaten, kota ataupun propinsi. Sedangkan pada kompetensi dasarnya yaitu mengenal perkembangan teknologi, komunikasi bahasanya, cara bertransportasi serta pengalaman menggunakannya. Indicator pada pembelajaran ini yaitu menjelaskan pengertian dari perkembangan teknologi, cara berkomunikasi dan bertransportasi kemudian membedakan transportasi dulu dan sekarang.

Tahap ini merupakan tahap dimana peneliti mempersiapkan segala keperluan penelitian sebelum melakukan action/ tindakan di lapangan. Dari mulai persiapan rencana pembelajaran, persiapan media pembelajaran hingga persiapan instrumen yang dibutuhkan dalam penelitian.

Tujuannya agar siswa dapat menjelaskan pengertian teknologi, jenisnya, bahasa komunikasinya yang lalu maupun sekarang. Selain itu, beberapa hal yang peneliti lakukan pada tahap perencanaan adalah sebagaiberikut:

a. Berdiskusi dengan guru kelas IV menegenai materi yang diajarkan

b. Mempersiapkan buku sumber belajar berupa buku paket bahasa Indonesia dan alat media belajar yang 
mendukung selama proses pembelajaran.

c. Menyiapkan lembar observasi, lembar tes dan daftar nilai.Siklus II

Pada pelaksanaan siklus II ini dilaksanakan dengan menggunakan metode mind map. Dengan hasil penelitian sebagai berikut:

\section{Perencanaan}

Pada perencanaan tindakan pembelajaran siklus II, terdiri dari satu pertemuan. Pembelajaran mengacu pada standar kompetensi dan kompetensi dasar, dengan standar kompetensinya yaitu mengenal sumber daya alam, kegiatan ekonomi, dan kemajuan teknologi dilingkungan kabupaten/ kota dan provinsi. Sedangkan pada kompetensi dasarnya yaitu mengenal perkembangan teknologi produksi, komunikasi dan transportasi serta pengalaman menggunakannya. Adapun indikator untuk kegiatan pembelajarannya yaitu menjelaskan pengertian dari perkembangan teknologi produksi, komunikasi dan transportasi, membedakan jenis teknologi produksi, komunikasi, transportasi masa lalu dan sekarang, menyebutkan macam-macam alat produksi, komunikasi transportasi masa lalu dan sekarang.

Tujuan pembelajaran yang akan dilaksanakan bertujuan agar siswa dapat menjelaskan pengertian teknologi produksi, komunikasi dan transportasi dengan benar, siswa dapat membedakan masing-masing 2 jenis teknologi produksi, komunikasi, transportasi masa lalu dan sekarang dengan benar, siswa dapat menyebutkan masing-masing 2 macam alat teknologi produksi, komunikasi, transportasi masa lalu dan sekarang. Materi yang akan disampaikan pada siklus
I yaitu perkembangan teknologi. Adapun metode yang digunakan dalam proses pembelajaran tersebut adalah metode mind map yangdirancang kedalam Rencana Pelaksanaan Pembelajaran (RPP).

Selain itu, beberapa hal yang peneliti lakukan pada tahap perencanaan adalah sebagai berikut:

a. Berdiskusi dengan guru kelas IV mengenai materi yang diajarkan.

b.Mempersiapkan buku sumber belajar berupa buku paket IPS dan alat media belajar lain yang mendukung selama proses pembelajaran.

c. Menyiapkan lembar observasi, lembar tes dan daftar nilai.

Pelaksanaan upaya meningkatkan hasil belajar siswa dalam penggunaan metode mind map.

\section{SIKLUS 1}

Pembelajaran siklus I dilaksanakan dengan mengimplementasikan metode Mind Map. Peneliti bertindak sebagai guru dan pengamat dibantu oleh observer yantu guru kelas IV. Pelaksanaan pembelajaran siklus 1 dilakukan pada hari Senin, 2 Oktober 2017 dalam waktu satu kali pertemuan selama dua jam pelajaran ( 2 x 35 menit), yaitu pada pukul 09.50-11.00 WIB. Kegiatan yang akan dilakukan yaitu kegiatan awal, kegiatan inti terdiri dari eksplorasi, elaborasi, konfirmasi, dan kegitan penutup.

Hasil belajar siswa kelas IV SD Negeri Kemantran 01 pada siklus 1 diperoleh data berupa tabel sebagai berikut:

Tabel 4.3 
Jurnal Bahasa, Sastra Indonesia, dan Pengajarannya

Volume 1- Nomor 2, April 2018, (Hlm 142-151)

Available online at: http://sasando.upstegal.ac.id

\section{Rekapitulasi Nilai Hasil Pembelajaran Siklus I}

\begin{tabular}{|c|c|c|c|c|}
\hline \multirow[b]{2}{*}{ No } & \multirow[b]{2}{*}{ Nama Siswa } & \multirow[b]{2}{*}{ Nilai } & \multicolumn{2}{|c|}{ Ketuntasan } \\
\hline & & & $\begin{array}{l}\text { Tun } \\
\text { tas }\end{array}$ & $\begin{array}{l}\text { Belum } \\
\text { Tuntas }\end{array}$ \\
\hline 1 & Aa Nurahman & 64 & $\sqrt{ }$ & \\
\hline 2 & Abi Firmansyah & 84 & $\sqrt{ }$ & \\
\hline 3 & Adi Nurhadi & 60 & $\sqrt{ }$ & \\
\hline 4 & Bandi & 60 & $\sqrt{ }$ & \\
\hline 5 & Beny Suparlan & 44 & & $\sqrt{ }$ \\
\hline 6 & Cinta Laelita & 40 & & $\sqrt{ }$ \\
\hline 7 & $\begin{array}{l}\text { Erla Rasha } \\
\text { Irmanto }\end{array}$ & 68 & V & $\mathrm{j}$ \\
\hline 8 & Friska Riska & 76 & $\sqrt{1}$ & \\
\hline 9 & Helena & 40 & & $\sqrt{ }$ \\
\hline 10 & Hena Kalina & 72 & V & \\
\hline 11 & Hifara & 32 & & $\sqrt{ }$ \\
\hline 12 & Jihan & 60 & V & \\
\hline 13 & Kaela Andiaka & 64 & V & \\
\hline 14 & Lina Herlina & 40 & & $\sqrt{ }$ \\
\hline 15 & Muhammad Rifai & 84 & V & \\
\hline 16 & $\begin{array}{l}\text { Muhammad } \\
\text { Rozak }\end{array}$ & 84 & V & \\
\hline 17 & Nanda Nandita & 80 & V & \\
\hline 18 & Nani Prisilia & 76 & 4 & \\
\hline 19 & Nanda prasetyo & 60 & V & \\
\hline 20 & Nunik halimah & 44 & & $\sqrt{ }$ \\
\hline 21 & Pina Putri Isrianto & 48 & & \\
\hline 22 & & & & $\sqrt{ }$ \\
\hline 23 & Putri Anastasia & 60 & V & \\
\hline 24 & & & & \\
\hline 25 & Ramdan Hamidar & & v & \\
\hline 26 & Raisya ananda & & & $\sqrt{ }$ \\
\hline 27 & Rina Rheniana & & & $\sqrt{ }$ \\
\hline 28 & Selvi Refita & & $\sqrt{ }$ & \\
\hline 29 & & & & \\
\hline 30 & Setiani Fitria & & & \\
\hline 31 & & & & \\
\hline 32 & $\begin{array}{lll}\text { Zifa Putri } & \text { Al } \\
\text { Zahra } & & \\
\end{array}$ & & & $\sqrt{ }$ \\
\hline & & & & \\
\hline & Zenita aprilia & & & \\
\hline $\mathbf{R a}$ & a-Rata & $\begin{array}{l}61,0 \\
9\end{array}$ & & \\
\hline Nil & i Terendah & 32 & & \\
\hline Nil & i Tertinggi & 84 & & \\
\hline Jur & lah Siswa Tuntas & & 19 & 11 \\
\hline $\begin{array}{l}\text { Per } \\
\text { Ke }\end{array}$ & $\begin{array}{l}\text { sentase } \\
\text { untasan Belajar }\end{array}$ & & $\begin{array}{l}69,5 \\
\%\end{array}$ & $30,5 \%$ \\
\hline Nil & i KKM & 60 & & \\
\hline
\end{tabular}

Berdasarkan Tabel 4.3 diperoleh data bahwa dari 30 siswa yang hadir, yang mencapai ketuntasan hanya 19 siswa atau 69,5\%, dan yang belum tuntas sebanyak 11 siswa atau $30,5 \%$.

\section{SIKLUS 2}

Pembelajaran siklus II Dilaksanakan dengan mengimplementasikan metode mind map. Peneliti bertindak sebagai guru dan pengamat dibantu oleh observer yaitu guru kelas IV. Pelaksanaan kegiatan pembelajaran pada siklus II dilaksanakanwaktu satu kali pertemuan selama dua am pelajaran (2 x 35 menit), yaitu pada pukul 09.50 - 11.00 WIB.

Kegiatan pembelajaran yang ingin dilakukan yaitu kegiatan pendahuluan, kegiatan inti erdiri dari eksplorasi, elaborasi dan konfirmasi serta kegiatan penutup.

Pada siklus II, hasil belajar siswa dalam pembelajaran Bahasa Indonesia Kelas IV SD Negeri Kemantran 01 adalah sebagai berikut:

Tabel 4.6

Rekapitulasi Nilai Hasil Pembelajaran Siklus II

\begin{tabular}{|c|c|c|c|c|}
\hline \multirow[b]{2}{*}{ No } & \multirow[b]{2}{*}{ Nama Siswa } & \multirow[b]{2}{*}{ Nilai } & \multicolumn{2}{|c|}{ Ketuntasan } \\
\hline & & & Tuntas & $\begin{array}{l}\text { Belum } \\
\text { Tuntas }\end{array}$ \\
\hline 1 & Aa Nurahman & 64 & $\sqrt{ }$ & \\
\hline 2 & Abi Firmansyah & 84 & $\sqrt{ }$ & \\
\hline 3 & Adi Nurhadi & 60 & $\sqrt{ }$ & \\
\hline 4 & Bandi & 60 & $\sqrt{ }$ & \\
\hline 5 & Beny Suparlan & 44 & $\sqrt{ }$ & \\
\hline 6 & Budi Budiana & 64 & $\sqrt{ }$ & \\
\hline 7 & Cinta Laelita & 40 & $\sqrt{ }$ & \\
\hline 8 & $\begin{array}{l}\text { Erla Rasha } \\
\text { Irmanto }\end{array}$ & 68 & & V \\
\hline 9 & Friska Riska & 76 & $\sqrt{ }$ & \\
\hline 10 & Helena & 40 & $\sqrt{ }$ & \\
\hline 11 & Hena Kalina & 72 & $\sqrt{ }$ & \\
\hline 12 & Hifara & 32 & $\sqrt{ }$ & \\
\hline 13 & Jihan & 60 & $\sqrt{ }$ & \\
\hline 14 & Kaela Andiaka & 64 & & V \\
\hline 15 & Lina Herlina & 40 & & $\sqrt{ }$ \\
\hline 16 & Muhammad Rifai & 84 & $\sqrt{ }$ & \\
\hline 17 & $\begin{array}{l}\text { Muhammad } \\
\text { Rozak }\end{array}$ & 84 & $\sqrt{ }$ & \\
\hline 18 & Nanda Nandita & 80 & $\sqrt{ }$ & \\
\hline 19 & Nani Prisilia & 76 & $\sqrt{ }$ & \\
\hline 20 & Nanda prasetyo & 60 & $\sqrt{ }$ & \\
\hline 21 & Nunik halimah & 44 & $\sqrt{ }$ & \\
\hline 22 & Pina Putri Isrianto & 48 & $\sqrt{ }$ & \\
\hline
\end{tabular}




\begin{tabular}{|l|l|l|l|l|}
\hline 23 & Putri Anastasia & \multicolumn{2}{l|}{60} & \multicolumn{2}{l|}{} \\
\hline 24 & Ramdan Hamidar & & $\sqrt{ }$ & \\
\hline 25 & Raisya ananda & & & $\sqrt{ }$ \\
\hline 26 & Rina Rheniana & & $\sqrt{ }$ & \\
\hline 27 & Selvi Refita & & $\sqrt{ }$ & \\
\hline 28 & Setiani Fitria & & & \\
\hline 29 & $\begin{array}{l}\text { Zifa Putri Al } \\
\text { Zahra }\end{array}$ & & & $\sqrt{ }$ \\
\hline 30 & Zenita aprilia & & $\sqrt{ }$ & \\
\hline Rata-Rata & $\mathbf{6 1 , 0 9}$ & & \\
\hline Nilai Terendah & $\mathbf{3 2}$ & & \\
\hline Nilai Tertinggi & $\mathbf{8 4}$ & & \\
\hline Jumlah Siswa Tuntas & & $\mathbf{2 5}$ & $\mathbf{5}$ \\
\hline $\begin{array}{l}\text { Persentase } \\
\text { Ketuntasan Belajar }\end{array}$ & & $\mathbf{6 9 , 5 \%}$ & $\mathbf{3 0 , 5 \%}$ \\
\hline Nilai KKM & $\mathbf{6 0}$ & & \\
\hline
\end{tabular}

Setelah dilaksanakan tindakan siklus II dengan menggunakan mind map pada pembelajaran bahasa Indonesia yang diikuti oleh 30 siswa kelas IV SD Negeri Kemantran o1 terjadi peningkatan hasil belajar siswa berupa kenaikan nilai rata- rata menjadi 78,9 dengan nilai terendah 50, nilai tertinggi 100 , serta ketuntasan belajar mencapai $87 \%$, atau sebanyak 25 dari 30 siswa yang mengikuti siklus II sudah tuntas belajar dengan mendapatkan nilai di atas KKM.

\section{PEMBAHASAN}

\section{Proses Pembelajaran yang Dilakukan Oleh Guru}

Menurut Anitah (2007:2.19) "hasil belajar merupakan kulminasi dari suatu proses yang telah dilakukan dalam belajar". Kulminasi akan selalu diiringi dengan kegiatan tindak lanjut. Perbandingan hasil proses pembelajaran yang dilakukan oleh guru pada tindakan siklus I dan II dapat digambarkan dalam grafik berikut ini:
Gambar 4.2 Grafik Perbandingan Proses Pembelajaran Yang Dilakukan Oleh Guru.

Siklus I dengan persentase $75 \%$. Apabila dilihat pada kriteria keberhasilan indakan, maka persentase $75 \%$ dengan kriteria baik sedangkan pada siklus II mengalami peningkatan dengan persentase sebesar 90\%. Apabila dilihat pada kriteria keberhasilan tindakan, maka persentase $90 \%$ dengan kriteria sangat baik. Perbandingan antara siklus I dan II mengalami peningkatan sebesar $21 \%$.

\section{Aktivitas BelajarSiswa}

Perbandingan aktivitas siswa dalam pelaksanaan pembelajaran bahasa Indonesia dengan menggunakan metode mind map pada siswa kelas IV SD Negeri Kemantran 01 setelah dilakukan tindakan siklus I dan II dapat digambarkan dalam grafik berikut ini:

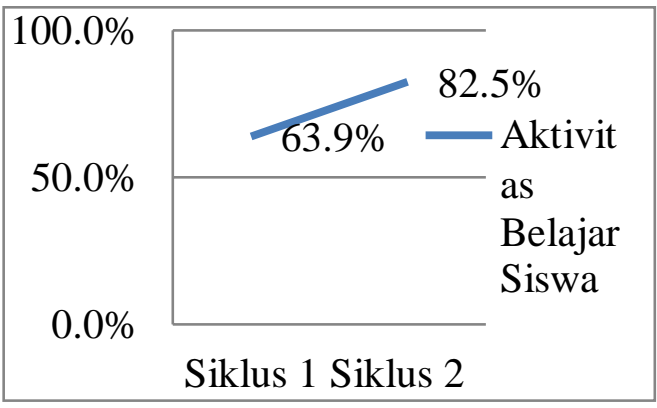

\section{Gambar 4.3 Grafik Perbandingan Aktivitas Belajar Siswa}

\section{Hasil Belajar}

Hasil belajar menjadi patokan dalam pelaksanaan penelitian. Secara keseluruhan, peningkatan hasil penelitian tersebut dapat dibandingkan dalam tabel rekapitulasi tes akhir serta aktivitas siswa pada pelaksanaan siklus I, dan siklus II sebagai berikut:

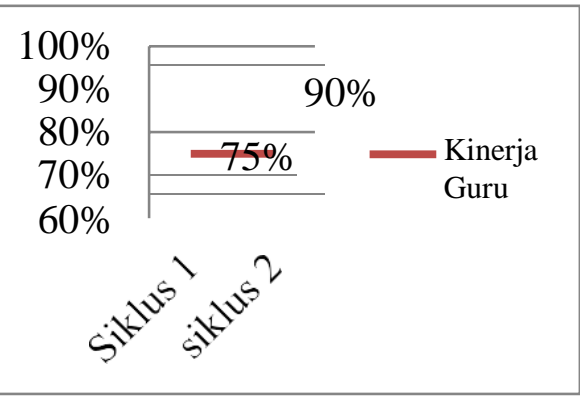


Table 4.7

\begin{tabular}{|l|l|l|}
\hline Pelaksanaan & Siklus I & Siklus II pe \\
\hline Hasil & Tes Akhir & Tes Akhik. \\
\hline Rata-rata & 69,5 & 78,9 \\
\hline Nilai Terendah & 32 & 50 \\
\hline Nilai Tertinggi & 84 & $100 \quad$ b. \\
\hline $\begin{array}{l}\text { Jumlah Siswa } \\
\text { Tuntas }\end{array}$ & 16 & 20 \\
\hline $\begin{array}{l}\text { Persentasi } \\
\text { Ketuntasan } \\
\text { Belajar }\end{array}$ & $65,2 \%$ & $87 \%$ \\
\hline
\end{tabular}

Perbandingan hasil belajar siswa dalam pelaksanaan pembelajaran bahasa Indonesia menggunakan metode Mind map pada siswa kelas IV SD Negeri Kemantran 01 Kecamatan Kramat Kabupaten Tegal setelah dilaksanakan tindakan siklus I dan siklus II dapat digambarkan dalam grafikberikut:

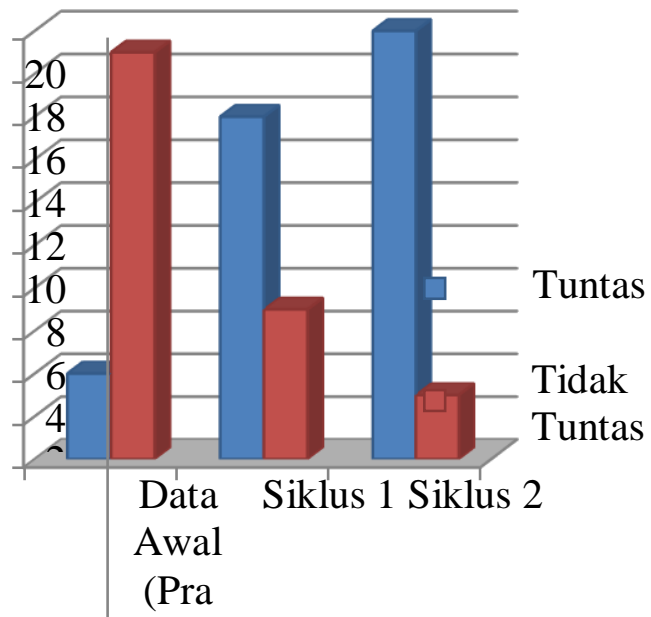

Grafik 4.4 Perbandingan Hasil Penelitian

\section{Metode Mind map}

Penerapan metode mind map dalam penelitian ini terbukti dapat meningkatkan hasil belajar siswa. Beberapa Dalam penelitian ini, halhal lain yang mendukung suksesnya penggunaan metode mind map dalam

mbelajaran adalah:
Guru memanfaatkan mind map secara berkelanjutan, sehingga siswa memahami konsep dari mindmap.

Siswa telah mempelajari materi yang akan di ajarkan menggunakan buku paket pelajaran Bahasa Indonesia, sehingga siswa mudah mempelajari kembali saat pembelajaran

dilaksanakan di kelas.

\section{Proses Pembelajaran Yang Dilakukan Oleh Guru}

Pada siklus I ada beberapa aspek yang tidak dilaksanakan oleh guru dan untuk siklus II guru melaksanakan semua aspek dan sesuai dengan RPP. Berdasarkan tabel 4.1 persentase siklus I sebesar $75 \%$ dengan kriteria baik, sedangkan pada siklus ke II di persentasekan sebesar 90\% dengan kriteria sangat baik dapat dilihat pada tabel 4.5 .

\section{Aktivitas Siswa}

Siswa menjadi obyek dalam penelitian ini. Siswa berperan penting dalam pelaksanaan penelitian. Dalam penelitian ini, aktivitas siswa mengalami peningkatan dari siklus I hingga siklus II, hal ini dapat dilihat pada tabel 4.2 dan

4.6. Perhatian yang diberikan guru dalam pembelajaran membuat siswa menjadi aktif dalam pembelajaran.

\section{SIMPULAN}

Pada proses pelaksanaan yang dilakukan oleh guru dengan menggunakan metode mind map di kelas IV SD Negeri Kemantran o1 menunjukkan perubahan yang positif yaitu adanya peningkatan pelaksanaan 
tindakan yang dilakukan oleh guru yaitu pada kegiatan belajar saat siklus I mencapai $75 \%$ atau dalam kriteria baik, sedangkan pada siklus II mengalami peningkatan mencapai $90 \%$ atau dalam kriteria sangat baik.

Aktivitas belajar siswa dalam proses pembelajaran perkembangan teknologi dengan menerapkan metode mind map di kelas IV SD Negeri Kemantran 01 pada siklus I yaitu $63,9 \%$ atau dalam kriteria baik, sedangkan untuk siklus II mengalami peningkatan dengan persentase $82,5 \%$ atau dalam kriteria sangat baik.

Hasil belajar ini dapat disimpulkan bahwa penerapan mind map sebagai metode pembelajaran terbukti efektif dalam meningkatkan hasil belajar IPS pada materi perkembangan teknologi siswa kelas IV SD Negeri Kemantran 01 Kecamatan Kramat Kabupaten Tegal tahun pelajaran 2017/2018. Hasil tes terbukti dengan meningkatnya hasil belajar siswa terhadap materi yang diajarkan pada setiap siklus dimulai dari data awal persentase ketuntasan siswa sebesar $17,4 \%$ atau 5 siswa saja yang tuntas, pada siklus I persentase ketuntasan siswa meningkat menjadi $69,5 \%$ atau 19 siswa yang tuntas, sedangkan siklus II persentase ketuntasan siswa meningkat menjadi $87 \%$ atau 25 siswa tuntas.

\section{DAFTAR PUSTAKA}

Anitah, S. W, dkk. (2008). Strategi Pembelajaran di SD. Jakarta: Universitas Terbuka

Arikunto, S. (2006). Penelitian

Tindakan Kelas. Jakarta: PT. Bumi

Aksara

Arikunto, S. (2010). Penelitian
Tindakan Kelas. Jakarta: PT. Bumi Aksara

Arifin. (2010). Evaluasi Pembelajaran.

Bandung: PT. Remaja Rosdakarya Hanifah, N. (2009). "Model Pembelajaran IPS di SD", dalam Buku Model Pembelajaran di Sekolah Dasa. (editor Dadan Djuanda dkk.). Sumedang: Universitas Pendidikan Indonesia.

Nurjannah, widia, dkk. 2014. DIKTAT Pembelajaran Bahasa Indonesia SD. Cirebon: UMC.

Mikarsa, Hera Lestari. 1999. Materi Pokok Pendidikan Anak SD. Jakarta: UT

Riduwan. 2012. Belajar Mudah Penelitian untuk Guru-Karyawan dan Peneliti Pemula. Bandung: Alfabeta

\section{Profil Singkat}

Lyswidia Andriarsih lahir di Tegal, 28 Desember 1984. Saat ini Bekerja sebagai dosen di Institut Agama Islam Bhakti Negara (IBN). Menempuh Pendidikan S1 di UMP dan S2 diUnnes 